\title{
P-12
}

\section{A Study of Chemical Compounds in Rhizophora Apiculata}

\author{
Nurul Huda Abdul Halim*, Nurul Auni Zainal Abidin and Ropisah Me
}

Fakulty of Applied Sciences, Universiti Teknologi MARA Negeri Sembilan, Kampus Kuala Pilah, Beting, 72000 Kuala

Pilah, Negeri Sembilan; E-mail: nurulhuda1596@ns.uitm.edu.my

Sources of natural antioxidants are primarily plant phenolics, which may occur in all parts of the plants such as fruits, vegetables, nuts, seeds, leaves, roots, and barks. Interest has considerably increased in finding naturally occurring chemical constituents for use in food or medicinal material to replace synthetic chemical. The chemical constituents of leaf, flower and stem samples were analyzed by using Gas Chromatography-Mass Spectrometry (GC-MS). The leaf was found to be rich 2-(2ethoxyethoxy)ethanol (26.45\%) and Kaur-16-ene (3.37\%), while 2-(ethoxyethoxy)ethanol (11.08\%) and butyl cyclohexyl ester 1,2-Benzenedicarboxylic acid (3.48\%) were the main components in the flower. Octadecamethyl cyclononasiloxane (5.24), Kaurene (3.39\%) and 1,2,3,4-tetramethoxy-5-(2-propenyl)-benzene (3.26) were the predominant constituents in the stem.

Keywords: Rhizophora apiculata, chemical constituents, antioxidants. 